\title{
An interdisciplinary study on the mode of action of probiotics in pigs
}

\author{
O. Simon ${ }^{1}$ \\ Speaker of the research group FOR 438 of the German Research Foundation, \\ Institute of Animal Nutrition, Faculty of Veterinary Medicine, Freie Universität Berlin \\ Brümmerstr. 34, D-14195 Berlin, Germany
}

(Received 5 May 2010; accepted 9 May 2010)

\begin{abstract}
An interdisciplinary research group granted by the German Research Foundation (FOR 438) tested various hypotheses and tired to develop a model for the mode of action of probiotics in pigs. The study included the fields of animal nutrition/digestion physiology, anatomy and histology of the intestinal mucosa, transport and secretory properties of the mucosa, microbiology of the intestinal tract, immune system (classes of intraepithelial lymphocytes, humoral responses), gene expression of the mucosa and finally the in vitro and in vivo resistance against infection with Salmonella.

Five trials with ten sows per treatment each and their piglets and two probiotic strains were included in this study. The studied bacterial strains were Enterococcus faecium NCIMB 10415 and Bacillus cereus var. toyoi NCIMB 40112.

Concluding from our studies and the published data of others, the effects of probiotics on performance are rarely significant. However, with one exception the incidence of post-weaning diarrhoea under the effect of both probiotics was significantly reduced in the trials of the research group. Furthermore, the identification frequency of various $E$. coli sero-pathovars relevant in post weaning diarrhoea was reduced in these animals. On the other hand, no significant modifications were found for the morphology and histology of the intestinal mucosa and also not on transport properties of this tissue. A further important finding was that the mode of action for probiotics is not unique but species or even strain specific. Most probably the studied probiotics act directly and/ or via modifications of the intestinal microbiota on the immune system (intraepithelial lymphocyte population).
\end{abstract}

KEY WORDS: pigs, probiotics, Enterococcus faecium, Bacillus versus

\footnotetext{
${ }^{1}$ Corresponding author: e-mail:osimon@zedat.fu-berlin.de
} 


\section{INTRODUCTION}

In animal nutrition probiotics are defined as viable microorganisms, which lead after sufficient oral intake to beneficial effects for the host animal because of an improvement of the intestinal microbial balance (Fuller, 1989). This definition differs from that used in human nutrition, where health promoting effects are the main scope of using microorganisms as additives in food (Sanders, 2000). Additionally, there are many other differences between the use in human and animal nutrition, respectively, like the frequency of intake, the supplemented portion of nutrient intake and especially the microorganisms used as probiotics. While in human nutrition in most cases strains of the genus Lactobacillus are used, in animal nutrition strains of Enterococcus faecium, or spore preparations of strains belonging to the genus Bacillus seem to dominate the market. At present 26 microorganism preparations are authorised for the use as feed additive in the EU.

For the use of microorganisms as feed additive a high stability during storage in a dry complete feed mixture as well as during technological processing is required. Another essential question is their fate and metabolic activity in the intestinal tract.

Most probiotics are approved for the claim of improving performance (daily weight gain, feed conversion ratio). However, the explanation of the mode of action is based mainly on hypotheses. This includes modifications of the intestinal microbial population, of the morphology and transport properties of the intestinal mucosa. Furthermore, modifications of the immune system are discussed. The main aspects were reviewed several years ago (Simon et al., 2001) and on this basis an interdisciplinary research group granted by the German Research Foundation (FOR 438) tested the various hypotheses and tried to develop a model for the mode of action of probiotics in pigs. Seven subprojects were coordinated in this study and the involved research groups belonged to the Freie Universität Berlin, the Charité Campus Benjamin Franklin Berlin and the Federal Institute of Risk Assessment. The study included the fields of animal nutrition/digestion physiology, anatomy and histology of the intestinal mucosa, transport and secretory properties of the mucosa, microbiology of the intestinal tract, immune system (classes of intraepithelial lymphocytes, humoral responses), gene expression of the mucosa and finally the in vitro and in vivo resistance against infection with Salmonella. For data evaluation a group of bioinformatics was included. This contribution aims to summarize the main findings of the study. More detailed information can be found using the list of publications at the homepage http://dfg-for438.de. 


\section{EXPERIMENTAL DESIGN}

Two bacterial strains, i.e. Enterococcus faecium NCIMB 10415 and Bacillucs cereus var. toyoi NCIMB 40112, were used throughout the study. Both are authorized in the EU for the use as feed additives in pigs. These microorganisms differ with regard to their natural habitat and their form of application. Enterococcus faecium occur naturally in the gastrointestinal tract of animals and man, and do not form spores and are therefore applied as desiccated vegetative cell preparations. The Bacillus cereus strain, which belongs to spore producing bacteria, was isolated from soil, and was applied as spore preparation due to their high stability. Both were included in the diets of sows and piglets, respectively, at a concentration of around $10^{9}$ viable counts per $\mathrm{kg}$ of feed. The precise concentration was measured by strain specific identification techniques. Attention was focused on an early inoculation of the gastrointestinal tract of the piglets with the probiotic strain. Therefore, in most of the trials the probiotic microorganism was applied already to the sows during the gestation period starting with 90 days antepartum. Five main trials with ten sows per treatment each and their piglets were included in this study. Details for application of the probiotics and time-points for sampling of faeces, digesta, blood or tissues for further analysis are summarized in Figure 1. In all subprojects samples

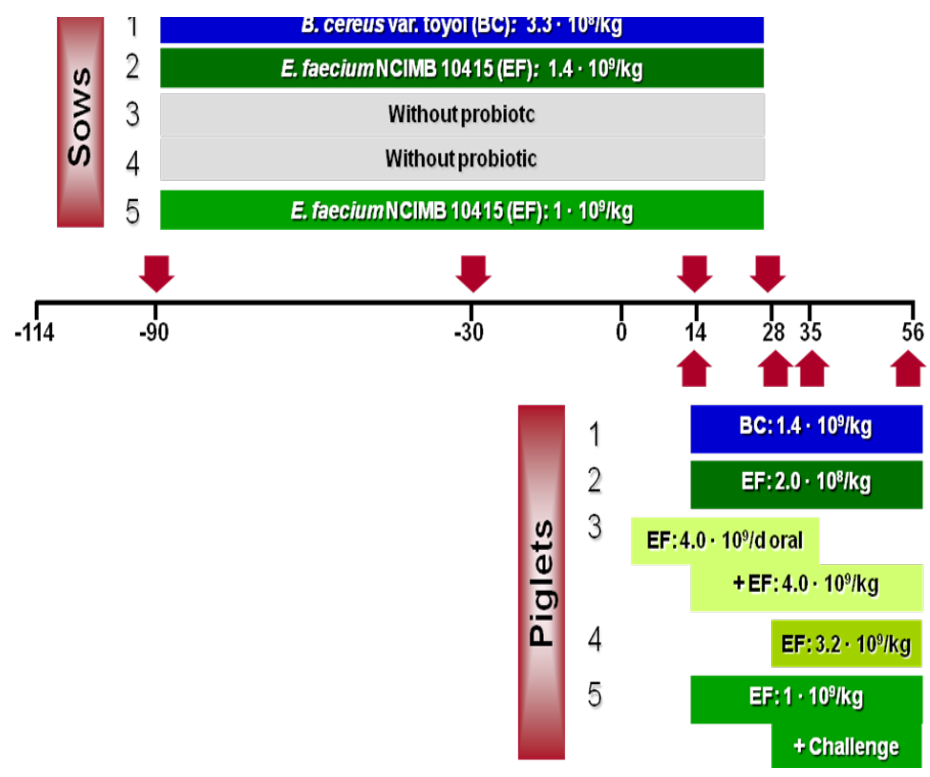

Figure 1. Design of Experiment 1 to 5. The time axis indicates days antepartum (-) and post-partum and arrows indicate time points of collecting the various samples 
from the same animals were analysed. In the applied management system piglets received until day 14 of life only sows milk, and pre-starter creep feed was offered starting with day 15 of life. Weaning was at day 28 after birth. For some parameters even more frequent sampling intervals were practised, e.g., in piglets day 7 and 31 of life.

\section{RESULTS AND DISCUSSION}

In-feed stability of the probiotic bacteria and their occurrence in the digestive tract of piglets. Within the project methods for specific enumeration of the probiotic bacterial strains in feed, digesta and faeces were developed. For Enterococcus faecium NCIMB 10415 a probe for colony hybridization was constructed using specific nucleotide sequences (Macha et al., 2004). Furthermore, a specific real time PCR assay for this strain was developed (Vahjen et al., 2007). Specific enumeration of Bacillus cereus var. toyoi was based on specific selective media controlled by a PCR protocol which targeted a sporulation gene of $B$. cereus var. toyoi (Taras et al., 2005).

Heat and storage stability of the two probiotic microorganisms were studied in preliminary experiments. Because the known high heat stability of bacterial spores feed containing Bacillus cereus var. toyoi $\left(0.9 \cdot 10^{9} \mathrm{CFU} / \mathrm{kg}\right)$ was pelleted at a temperature in the conditioner of $82^{\circ} \mathrm{C}$. The recovery of viable counts after pelleting was $95 \%$, confirming the high heat stability of these kinds of spore preparations. In case of Enterococcus faecium NCIMB 10415 supplemented feed the temperature in the conditioner was set to $50,60,70$ and $80^{\circ} \mathrm{C}$, respectively, resulting in a recovery of viable counts of the probiotic organism of 103, 95, 52 and $37 \%$, respectively. Therefore, it was decided to pellet the feed throughout the study at a temperature in the conditioner of $50^{\circ} \mathrm{C}$, which leads to a temperature of the pellets after the dye of approximately $60^{\circ} \mathrm{C}$.

Using the strain specific identification techniques for quantitative identification of the probiotics it was possible to follow the time-course of occurrence of the probiotic along the digestive tract in piglets during the suckling period and after weaning. Table 1 presents the probiotic concentrations in faeces and digesta of the piglets in Trials 1 to 4 at day 7 and 56, respectively. More detailed information is reported in several publications (Macha et al., 2004; Taras et al., 2005, 2007; Vahjen et al., 2007).

One of the main findings was that in case the sow received probiotic supplemented feed already during the gestation period, the probiotic bacteria were transferred to the sucking piglets before supplemented pre-starter was 
Table 1. Mean rounded probiotic concentration (cfu) in feed, faeces (sows and piglets) and in digesta of piglets during the early suckling period and four weeks after weaning

\begin{tabular}{lcccc}
\hline Item & Trial 1 & Trial 2 & Trial 3 & Trial 4 \\
\hline Probiotic strain $^{1}$ & $\begin{array}{c}\text { B. } \\
\text { cereus }\end{array}$ & $\begin{array}{c}\text { E. } \\
\text { faecium }\end{array}$ & $\begin{array}{c}E . \\
\text { faecium }\end{array}$ & $\begin{array}{c}E . \\
\text { faecium }\end{array}$ \\
& $3 \times 10^{8}$ & $1 \times 10^{9}$ & - & - \\
Probiotic cfu/kg feed of sows & - & - & $4 \times 10^{9}$ & - \\
Probiotic cfu/day, oral (day 1 to 34) & & & - \\
Probiotic cfu/kg feed (day 15 to 28) & $1 \times 10^{9}$ & $2 \times 10^{8}$ & $4 \times 10^{9}$ & - \\
Probiotic cfu/kg feed (day 29 to 56) & $1 \times 10^{9}$ & $2 \times 10^{8}$ & $4 \times 10^{9}$ & $3 \times 10^{9}$ \\
Probiotic cfu/g faeces (sow, day 7 p.p.) & $3 \times 10^{5}$ & $1 \times 10^{5}$ & - & - \\
Probiotic cfu/g faeces (piglets, day 7 p.p.) & $6 \times 10^{4}$ & $3 \times 10^{4}$ & $6 \times 10^{8}$ & - \\
Probiotic cfu/g stomach content (piglets, day 56 p.p.) & $1 \times 10^{5}$ & $3 \times 10^{3}$ & $2 \times 10^{5}$ & $3 \times 10^{5}$ \\
Probiotic cfu/g jejunum content (piglets, day 56 p.p.) & $2 \times 10^{5}$ & $3 \times 10^{3}$ & $2 \times 10^{6}$ & $1 \times 10^{6}$ \\
Probiotic cfu/g colon content (piglets, day 56 p.p.) & $5 \times 10^{5}$ & $2 \times 10^{4}$ & $7 \times 10^{7}$ & $2 \times 10^{4}$ \\
\hline${ }^{1}$ Bacillucs cereus var. toyoi NCIMB 40112 and Enterococcus faecium NCIMB $10415 ;$ & \\
${ }^{2}$ the probiotic was dosed once daily; ${ }^{3}$ weaning at day 28 postpartum & &
\end{tabular}

available and was found in all sections of the gastrointestinal tract. This took most likely place by contact with the maternal faeces. The concentration of $B$. cereus increases after weaning by one order of magnitude, while the concentration of the E. faecium probiotic was not considerably increased after intake of supplemented feed by piglets. The highest intestinal concentrations of the E. faecium probiotic were reached due to the daily high oral dosage from birth on. For both probiotics, the ability to colonize very fast the digestive tract of piglets was demonstrated, however, their concentration remains rather low compared to the total luminal bacterial population.

Effects of the probiotics on performance of weaned piglets and diarrhoea incidence. Attention was focused on performance parameters (feed intake, weight gain, feed conversion ratio) during four weeks after weaning. The results were published by Taras et al. (2005, 2006, 2007). E. faecium NCIMB 10415 had no significant effects on overall performance of weaned piglets in none of the treatment variants, although the feed efficiency was improved numerically by about $1 \%$. Supplementation with Bacillus cereus var. toyoi led to an increase in average daily gain by $11 \%$ which was, however, not significant. The only significant effect in this trial was an improvement of feed conversion ratio by $8 \%(\mathrm{P}<0.01)$ compared to control animals. Precaecal nutrient and amino acid digestibility was also measured. In one of the trials precaecal digestibility of most amino acids was significantly increased in piglets receiving E. faecium NCIMB 10415. However, this observation was not confirmed by repeating the experiment. No other effects on nutrient digestibility were recorded.

The influence of the probiotics was more pronounced on the incidence of 


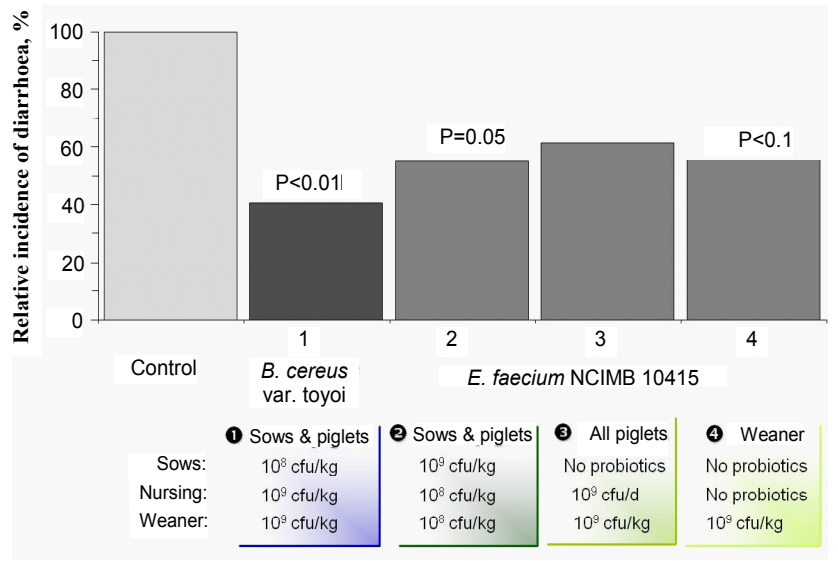

Figure 2. Effects of the probiotic bacteria strains Enterococcus feacium NCIMB 10415 and Bacillus cereus var. toyoi on the incidence of post-weaning diarrhoea in experiments 1 to 4 . Incidence of diarrhoea in control animals was set $100 \%$

post-weaning diarrhoea (Figure 2; Taras et al., 2005, 2006). Both probiotics reduced the incidence of post-weaning diarrhoea compared to the control group. This effect was significant in three out of four trials. The reduction ranged from 39 to $59 \%$ and the magnitude of reduction seemed to be mainly influenced by the incidence of diarrhoea in the control animals. This was only $11 \%$ in Trial 3 , where the reduction was not significant and less pronounced, while all other trials had diarrhoea incidences of at least $40 \%$ in the control group. Due to the economic importance, one main reason of using probiotic feed additives in pig rearing might be the reduction of post-weaning diarrhoea.

Effects of the probiotics on the gastrointestinal microbiota of weaned piglets. Various attempts have been made to describe effects of the probiotics on the bacterial population in the gastrointestinal tract of piglets during the first eight weeks of life. Cultural and nucleic acid based techniques were applied. As expected, the limited potential of cultivation techniques to characterize the complex intestinal was shown. For instance, applying cultivation techniques for determination of total coliform counts in colon of piglets did not reveal any effect of E. faecium NCIMB 10415 on the concentration of this bacterial group. However, using the same samples for serotyping of $E$. coli isolates revealed a remarkable decline in the frequency of $\beta$-haemolytic and 0141 serovars of Escherichia coli in the probiotic treated piglets (Figure 3; Scharek et al., 2005). The reducing effect on isolation frequency of various $E$. coli serovars was even more pronounced for Bacillus cereus var. toyoi (Scharek et al., 2007a). 


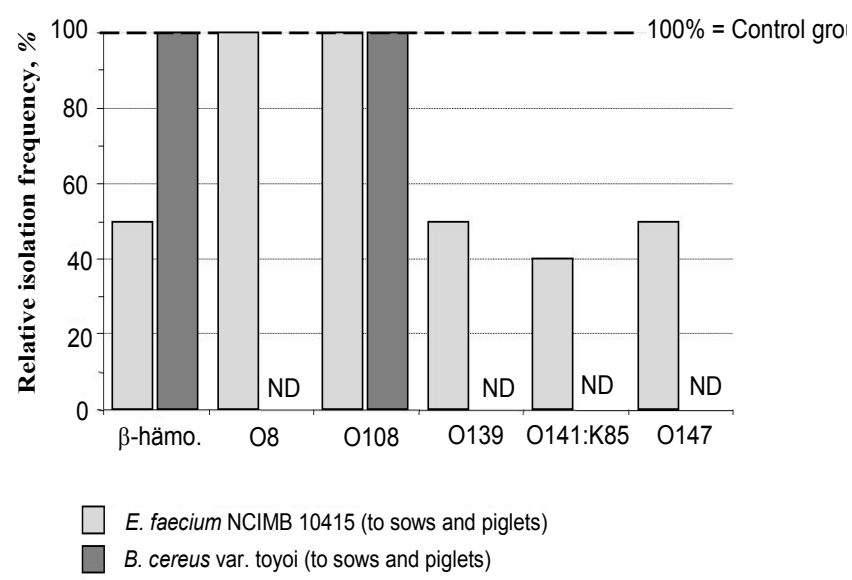

Figure 3. Isolation frequency of Escherichia coli serogroups in experiments 1 and 2. Samples were collected from the terminal colon of piglets during $14^{\text {th }}$ to $56^{\text {th }}$ day of life. ND indicates non detectable serovars

Furthermore, the frequency of four toxin and five adhesion genes of putative pathogenic Escherichia coli was monitored by a multiplex PCR assay (Taras et al., 2006) and the variety of virulence gene profiles of Escherichia coli in clinically healthy pigs was characterized (Schierack et al., 2006).

Another important observation was the reduced transfer of Chlamydia from infected sows to the piglets in E. faecium NCIMB 10415 treated animals, using species specific PCR, fluorescence in situ hybridization and immunohistology techniques (Pollmann et al., 2005). Furthermore, it was shown, that the presence of the same probiotic coincided with reduced E. faecalis in the intestine of piglets (Vahjen et al., 2007). These findings indicate generally a reduced intestinal pathogen load in piglets from the probiotic treated groups. Studies on the effects of E. faecium NCIMB 10415 on the intestinal Lactobacillus population have shown significant modifications on the species level (Klär, 2008).

As a side result of the project four novel bacterial species were isolated and characterized from the intestine of piglets, i.e. Treponema berlinense sp. nov., Treponema porcinum sp. nov. (Nordhoff et al., 2005), Veilonella magna sp. nov. (Kraatz and Taras, 2008) and Olsenella umbonata sp.nov. (Kraatz et al., 2010).

A further important outcome of the project was the characterization of the permanent porcine intestinal epithelial cell line IPEC-J2 for in vitro studies of microbial pathogenesis (Schierack et al., 2006). Using this cell line in an in vitro infection model, K. Tedin (Institute for Microbiology and Epizootics, Freie Universität Berlin) demonstrated the expression of an extracellular 
factor by E. faecium NCIMB 10415, which reduces the rate of invasion of the IPEC-J2 cells by Salmonella enteritica serovar Typhimurium. This factor is not identified yet and seems to be strain specific (Figure 4). Based on this observation the challenge trial (Trial 5; Szabo et al., 2009) was designed and performed.

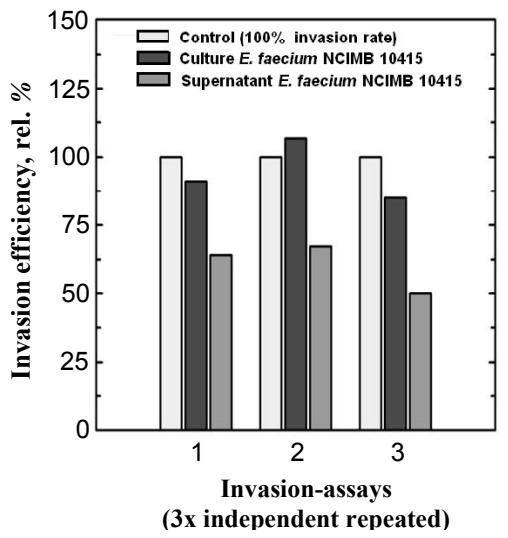

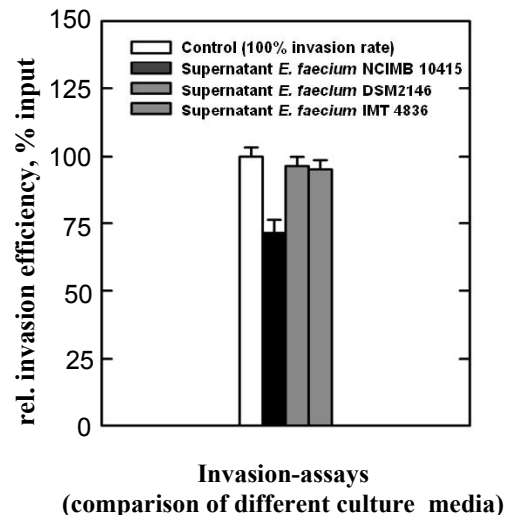

Figure 4. Effects of culture media from Enterococcus faecium NCIMB 10415 and from other $E$. faecium strains on Salmonella Typhimurium invasion of IPEC-J2 cells (Functional analysis - ex vivo/in vitro)

Effects of the probiotics on structural and functional properties of the intestinal mucosa. Because pronounced effects of probiotic microorganisms on intestinal mucosa morphology have been shown previously (Klein and Schmidts, 1997; Baum et al., 2002) these hypothesis was studied carefully within the project. A clarification of these kinds of effects was particularly important because the observations indicated an increase in villus height and mucosa surface in the jejunum of probiotic treated pigs which could be an influencing factor on nutrient absorption. Control animals and piglets from probiotic treated sows and piglets receiving the two probiotics, respectively, starting with day 15 , were subjected to this investigation at an age of 14, 28, 35 and 56 days (5 piglets per time-point and treatment). Tissue samples from duodenum, jejunum, ileum, caecum and colon were collected and examined for morphology and histochemistry (Scharek et al., 2005; Reiter et al., 2006). No significant effects of the probiotics were found on villi height, crypt depth, enlargement factor (according to Wiese et al., 2003) and number of goblet cells. Analysis of villi shape by means of scanning electron microscopy revealed a high variability in all groups, which was not related to the nutritional treatment.

Functional properties of samples from the mid-jejunum of the same animals were studied by Ussing chamber technique (Lodemann et al., 2006, 2008). 
For evaluation of barrier function mannitol fluxes and tissue resistance were measured. Absorptive and secretory processes where assessed by means of Na-coupled transport of glucose and glutamine and stimulation of ion secretion by PEG2. Although an increased short circuit in tissues from piglets of the $E$. faecium NCIMB 10415 treatment was measured after addition of glucose and L-glutamine and in tissues of piglets receiving Bacillus cereus var. toyoi only after addition of L-glutamine, these parameters did not reach significance. Summarizing, no significant and inconsistent influence was found on absorptive and secretory properties of the jejunal mucosa due to the intake of the studied probiotics. Thus, the findings of Breves et al. (2000), who have observed a stimulated Na-coupled glucose and peptide transport in small intestinal tissue from piglets fed with Bacillus cereus var. toyoi containing diets were not reproduced in our studies.

Effects of the probiotics on the immune cell population. The development of mucosal immunity of piglets was monitored by isolation and detection of the intestinal lymphocyte cell population from the proximal jejunal epithelium and the continuous Peyer's patches. In addition, levels of intestinal IgA were measured in piglets and serum IgG levels in sows and piglets. For enumeration of intraepithelial lymphocyte population fluorescence activated flow cytometry was applied, in some cases expanded by fluorescence microscopy. The detailed results are documented in several publications (Scharek et al., 2005, 2007b,c; Schierack et al., 2007, 2009). Following only some of the main findings are summarized.

An unexpected but reproducible finding was the different effect of the two studied probiotic bacteria on the level of intraepithelial lymphocytes in piglets. Generally, a reduction of cytotoxic cells $(\mathrm{CD} 8+)$ in jejunal epithelium was monitored in piglets receiving E. faecium NCIMB 10415 supplemented feed. Under these conditions serum IgG was also reduced after weaning. In contrast, under the influence of Bacillus cereus var. toyoi the population of intraepithelial CD8+ T cells was significantly enhanced compared to control animals. The effects on the intraepithelial lymphocyte population were found already before weaning. It was concluded, that feeding the probiotics to the sows during gestation might be the best way to modulate the immune status of the piglets at a very early developmental stage. The studied probiotics differed also in their effect on the IgA level in faeces of piglets (by Bacillus cereus var. toyoi increasing before weaning; by E. faecium NCIMB 10415 decreasing after weaning).

In a further trial the potential of Bacillus cereus var. toyoi to alter the immune system of piglets was shown (Schirack et al., 2007), e.g., their specific proliferation response of peripheral blood mononuclear cells to influenza vaccination antigens was significantly higher compared to control animals. In addition, further parameters of systemic immunity differed significantly between the treatment 
Further attempts have been made to investigate whether expression o genes involved in restoration of intestinal epithelial continuity following injury or environmental challenges might be affected by intake of the $E$. faecium probiotic. Therefore, the developmental gene expression pattern of trefoil factor family peptides and selected pathway related genes were studied in control and probiotic piglets following the sampling pattern and employing real-time PCR and immunoblotting (Scholven et al., 2009). Differential regulation of gene expression during development of the porcine intestine was observed in this study however, the probiotic treatment did not show any significant influence.

Effects of the E. faecium NCIMB 10415 probiotic on Salmonella infection of piglets. As reported by Casey et al. (2007) in piglets fed a diet supplemented with a mixture of fife probiotic bacteria revealed after a challenge with Salmonella serovar Typhimurium reduced incidence, severity and duration of diarrhoea and a reduced load of Salmonella. Furthermore, applying the in vitro infection model in our study, the ability of factors produced by E. faecium NCIMB 10415 to decrease the invasion rate of intestinal epithelial cells by Salmonella enteritica serovar Typhimurium was found (Figure 4). Therefore, it was decided to perform a challenge experiment with Salmonella enterica serovar Typhimurium DT104 in piglets of control treatment and E. faecium treatment (sows and piglets), respectively (Szabo et al., 2009). Piglets in both groups (46 control, 43 probiotic treaded) were challenged on day 29 post-partum with the Salmonella strain by intragastric application. Various clinical parameters and presence and numbers of Salmonella enteritica serovar Typhimurium in faeces and various tissues were monitored during four weeks post infectionem. The unexpected result of the challenge experiment was that faecal excretion and colonization of Salmonella in organs were significantly increased in piglets fed the E. faecium probiotic (Figure 5). On the other hand, the humoral immune response against Salmonella in these animals was significantly greater than in control animals. As in previous trials, again a reduction in the population of CD8+ intraepithelial lymphocytes was monitored in the probiotic treated piglets. That could have been a critical disadvantage under these conditions and involved in restoration of intestinal epithelial continuity following injury or of antibodies against the pathogen and the piglets were completely dependent on the functional cellular immunity during the first contact with the pathogen.

Therefore, it can be concluded that the response of the animals to infections is dependent on both, the microbial and the immunological status. Another conclusion is that despite of the great importance of in vitro infection models in research the findings cannot considered as valid for in vivo conditions without confirmation in animal experiments. 


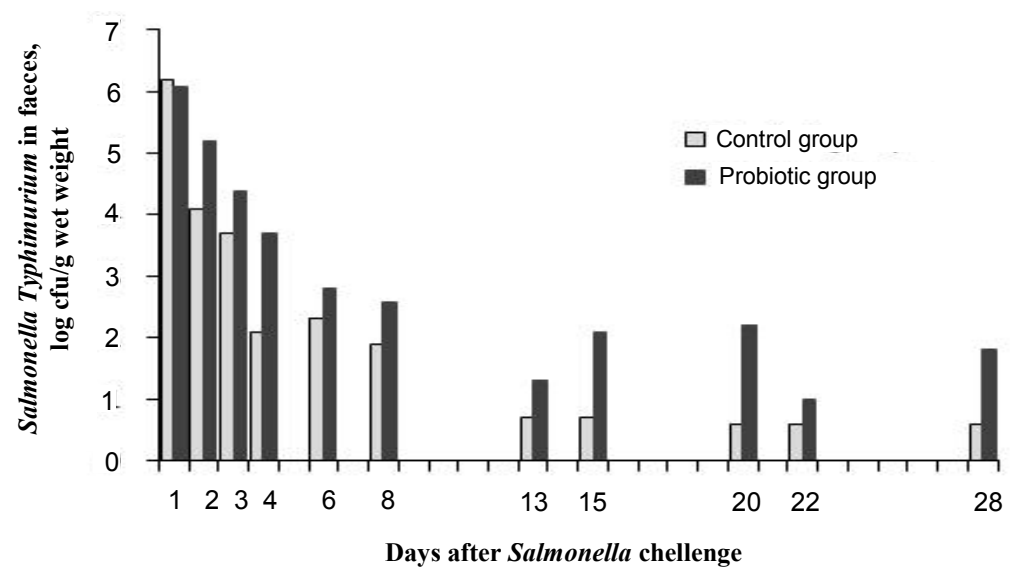

Figure 5. Faecal excretion of Salmonella Typhimurium in piglets form control and Enterococcus faecium NCIMB 10415 treated groups

Development of a hypothesis for the mode of action of probiotics in piglets. According to previous hypotheses one main effect of both studied probiotics was the modification of intestinal bacterial communities. Although the probiotic strains did not exceed concentration of $10^{5}$ to $10^{6} \mathrm{CFU}$ per g digesta, clear modifications were shown on the isolation frequency of several $E$. coli serovars, the concentration of E. faecalis and the Lactobacillus populations. Generally, a reduced load with pathogenic bacteria and a reduced incidence of post-weaning diarrhoea was found under the influence of both bacterial probiotics used in this study.

However, especially the analysis of immune parameters revealed differences in the mode of action between Enterococcus faecium NCIMB 10415 and Bacillus cereus var. toyoi NCIMB 40112. Furthermore, these findings imply that the modification of immune parameters together with the bacterial status play a central role in the effects provoked by probiotics. The most pronounced effect was observed on the population of intraepithelial T-lymphocytes in piglets' jejunum, which was generally decreased by Enterococcus faecium NCIMB 10415 and increased by Bacillus cereus var. toyoi NCIMB 40112. Thus, bacterial probiotics do not have an uniform mode of action but act species-specific or even strainspecific as shown by the in vitro infection trial.

On this basis, the discrepancies between the in vitro and in vivo infection studies with Salmonella serovar Typhimurium and the effect of the E. faecium probiotic on infection course require some additional discussion. First of all, we have learned that such an in vitro infection model may be of value to identify factors influencing functional properties of epithelial cells, but it cannot reflect the 
piglets treated with the E. faecium probiotic compared to control animals although the invasion rate of epithelial cells was reduced in vitro? The most probable explanation is a reduced concentration of intraepithelial T-lymphocytes and therefore a reduced local immunity in piglets receiving the $E$. faecium probiotic. In addition, the animal flock was free of Salmonella and no specific antibodies were transferred from the sows to the piglets (Szabo et al., 2009). This hypothesis needs further confirmation and for this reason a trial is planned following the same experimental design, but using Bacillus cereus var. toyoi as feed additive, which was shown to act immune stimulatory and to increase the population of intraepithelial T-lymphocytes.

In contrast to previous hypotheses on the mode of action of probiotics, in our model the immune response of the animals and its interaction with intestinal bacterial communities play a key role.

\section{REFERENCES}

Baum B., Liebler-Tenorio E.M., Enss M.L., Pohlenz J.F., Breves G., 2002. Saccharomyces boulardii and Bacillus cereus var. toyoi influence the morphology and the mucins in the intestine of pigs. Z. Gatroenterol. 40, 277-284

Breves G., Walter C., Burmester M., Schröder B., 2000. In vitro studies on the effects of Saccharomyces boulardii and Bacillus cereus var. toyoi on nutrient transport in pig jejunum. J. Anim. Physiol. Anim. Nutr. 84, 9-20

Casey P.G., Gardiner G.E., Casey G., Brandshaw B., Lawlor P.G., Lynch P.R., Leonard F.C., Stanton C., Ross R.P., Fitzgerald G.F., Hill C., 2007. A fife strain probiotic combination reduces pathogen shedding and alleviates disease sings in pigs challenged with Salmonella enteritica serovar Typhimurium. Appl. Environ. Microbiol. 73, 1858-1863

Fuller R., 1989. Probiotics in man and animals. J. Appl. Bacteriol. 66, 365-378

*Klär I., 2008. Einfluss der Verfütterung des Probiotikums E. faecium NCIMB 10415 im frühen postnatalen Stadium auf die Zusammensetzung und Stoffwechselaktivität der gastrointestinalen Mikrobiota bei Ferkeln. Dissertation, Freie Universität Berlin, ISBN: 978-3-86664-494-6

Klein U., Schmidts H.L., 1997. Zum Einfluss des Bioregulators Parciflor auf die Morphologie der Dünndarmmukosa beim Schwein. Proc. Soc. Nutr. Physiol. 61, 41 (Abstr.)

*Kraatz M., Taras D., 2008. Veillonella magna sp. nov., isolated from the jejunal mucosa of a healthy pig, and emended description of Veillonella ratti. Int. J. Syst. Evol. Microbiol. 58, 2755-2761

*Kraatz M., Wallace R.J., Svensson L., 2010. Olsenella umbonata sp.nov., a microaerotolerant anaerobic lactic acid bacterium from the sheep rumen and pig jejunum, and emended description of Olsenella, Olsenella uli and Olsenella profuse. Int. J. Syst. Evol. Microbiol. (accepted)

*Lodemann U., Hübener K., Jansen N., Martens H., 2006. Effects of Enterococcus faecium NCIMB 10415 as probiotic supplement on intestinal transport and barrier function of piglets. Arch. Anim. Nutr. 60, 35-48

*Lodemann U., Lorenz B.M., Weyrauch K.D., Martens H., 2008. Effects of Bacillus cereus var. toyoi as probiotic feed supplement on intestinal transport and barrier function in piglets. Arch. Anim. Nutr. 62, 87-106 
*Macha M., Taras D., Vahjen W., Arini A., Simon O., 2004. Specific enumeration of the probiotic strain Enterococcus faecium NCIMB 10415 in the intestinal tract and in faeces of piglets and sows. Arch. Anim. Nutr. 58, 443-452

*Nordhoff M., Taras D., Macha M., Tedin K., Busse H.-J., Wieler L.H., 2005. Description of Treponema berlinense sp. nov. and Treponema porcinum sp. nov., two novel spirochaetes isolated from porcine faeces. Int. J. Syst. Bact. 55, 1675-1680

*Pollmann M., Nordhoff M., Pospischil A., Tedin K., Wieler L.H., 2005. Effects of a probiotic strain of Enterococcus faecium on the infection rate of Chlamydia in swine. Infect. Immunity 73, 4346-4353

*Reiter K., Eggebrecht S., Drewes B., Riess M., Weyrauch K.D., 2006. Effects of Enterococcus faecium and Bacillus cereus var. toyoi on the morphology of the intestinal mucous membrane in piglets. Biologia (Bratisl) 61, 803-809

Sanders M.E., 2000. Consideration for the use of probiotic bacteria to modulate human health. J. Nutr. 130, 384S-390S

*Scharek L., Altherr B.J., Tölke C., Schmidt M.F.G., 2007b. Influence of the probiotic Bacillus cereus var. toyoi on the intestinal immunity of piglets. Vet. Immunol. Immunopathol. 120, 136147

*Scharek L., Guth J., Filter M., Schmidt M.F.G., 2007c. Impact of the probiotic bacteria Enterococcus faecium NCIMB 10415 (SF68) and Bacillus cereus var. toyoi NCIMB 40112 on the development of serum IgG and faecal IgA of sows and their piglets. Arch. Anim. Nutr. 61, 223-234

*Scharek L., Guth J., Reiter K., Weyrauch K.D., Taras D., Schwerk P., Schierack P., Schmidt M.F., Wieler L.H., Tedin K., 2005. Influence of a probiotic Enterococcus faecium strain on development of the immune system of sows and piglets. Vet. Immunol. Immunopathol. 105, 151-161

*Schierack P., Filter M., Scharek L., Toelke C., Taras D., Tedin K., Haverson K., Lübke-Becker A., Wieler L.H., 2009. Effect of Bacillus cereus var. toyoi on immune parameters of pregnant sows. Vet. Immunol. Immunopathol. 127, 26-37

*Schierack P., Nordhoff M., Pollmann M., Weyrauch K.D., Amasheh S., Lodemann U., Jores J., Tachu B., Kleta S., Blikslager A., Tedin K., Wieler L.H., 2006. Characterization of a porcine intestinal epithelial cell line for in vitro studies of microbial pathogenesis in swine. Histochemistry Cell Biol. 125, 293-305

*Schierack P., Steinrück H., Kleta S., Vahjen W., 2006. Virulence factor gene profiles of Escherichia coli isolates from clinically healthy pigs. Appl. Environ. Microbiol. 101, 1357-1366

*Schierack P., Wieler L.H., Taras D., Herwig V., Tachu B., Hlinak A., Schmidt M.F.G., Scharek L., 2007. Bacillus cereus var. toyoi enhanced systemic immune response in piglets. Vet. Immunol. Immunopathol. 118, 1-11

*Scholven J., Taras D., Sharbati-Tehrani S., Gabler C., Huber O., Meyer zum Bueschenfelde D., Blin N., Einspanier R., 2009. Intestinal expression of TFF and related genes during postnatal development in a piglet probiotic trial. Cell. Physiol. Biochem. 23, 143-156

Simon O., Jadamus A., Vahjen W., 2001. Probiotic feed additives - effectiveness and expected modes of action. J. Anim. Feed Sci. 10, Suppl. 1, 51-67

*Szabó I., Wieler L.H., Tedin K., Scharek-Tedin L., Taras D., Hensel A., Appel B., Nöckler K., 2009. Influence of a probiotic strain of Enterococcus faecium on Salmonella Typhimurium DT104 infection in swine as animal model. Infec. Immunity 75, 2621-2628

*Taras D., Vahjen W., Macha M., Simon O., 2005. Response of performance characteristics and fecal consistency to long-lasting dietary supplementation with the probiotic strain Bacillus cereus var. toyoi to sows and piglets. Arch. Anim. Nutr. 59, 405-417 
*Taras D., Vahjen W., Macha M., Simon O., 2005.2006. Performance, diarrhea incidence, and occurrence of Escherichia coli virulence genes during long-term administration of a probiotic Enterococcus faecium strain to sows and piglets. J. Anim. Sci. 84, 608-617

*Taras D., Vahjen W., Simon O., 2007. Probiotics in pigs - modulation of their intestinal distribution and of their impact on health and performance. Livest. Sci. 108, 229-231

*Taras D., Vahjen W., Simon O., 2007. Effect the probiotic Enterococcus faecium NCIMB10415 on cell numbers of total Enterococcus spp., E. faecium and E. faecalis in the intestine of piglets. Curr. Issues Intest. Microbiol. 8, 1-7

Wiese F., Simon O., Weyrauch K.D., 2003. Morphology of the small intestine of weaned piglets and a noval method for morphometric evaluation. Anat. Histol. Embryol. 32, 102-109

*These publications result from the research group (FOR 438) of the German Research Foundation "Integrative Analysis of the Mode of Action of Probiotics in Pigs" 